\title{
National Breast Screening Programs across Europe
}

\author{
Florentia Peintinger \\ Institute of Pathology, Medical University of Graz, Graz, Austria; Department of Gynecology, \\ General Hospital Hochsteiermark, Leoben, Austria
}

\section{Keywords}

Breast cancer $\cdot$ Screening program · Mammography

\section{Abstract}

Background: Mammography screening programs in Europe revealed a $25-30 \%$ breast cancer mortality reduction in women between 50 and 74 years. Early cancer detection and less radical treatment in dedicated multidisciplinary breast centers have improved breast cancer care. Breast population-based screening (persons are individually identified and personally invited to attend screening) is intended to detect breast cancer at an early stage to enable lower mortality rates. Methods: The status of implementation of cancer screening programs among European countries, quality parameters and possible differences will be reviewed. Results: Implementation of the recommended maximum age range was adopted in most programs. Almost all the European countries established digital mammography as the method of screening instead of screen-film mammography. Inequalities in implementation of cancer screening in the European Union have been observed. Conclusion: Improvement of data quality and mortality registries linked to the screening programs are needed.

(c) 2019 S. Karger AG, Basel

\section{Background}

Breast cancer burden is high in the European Union (EU; European age-standardized rate, 108.8/100,000) [1] and is expected to rise in some countries (Fig. 1).
In 2003, the European Council presented recommendations on cancer screening to reduce the incidence of cancer in Europe [2]. Implementation of populationbased national cancer screening programs was based on approximately 30 recommendations with appropriate quality assurance.

In 2006, the European Commission published the 4th edition of the European guidelines for quality assurance in breast cancer screening and organization of diagnosis in order to promote implementation of organized population-based breast screening programs and to assure quality parameters such as the proportion of women who attended screening [3].

Also, the European Code against Cancer (ECAC) was updated in 2015, recommending the participation in organized screening programs.

Mortality rates are used to show the effectiveness of a second prevention test, and mammography screening programs in Europe revealed a $25-30 \%$ breast cancer mortality reduction in women between 50 and 74 years. Early cancer detection and less radical treatment in dedicated multidisciplinary breast centers have improved breast cancer care. However, controversy exists regarding age at entry into screening ( 40 vs. 50 years) and interval of screening (annually vs. biennial) excluding women at high risk of breast cancer such as gene mutation carriers who should be screened annually by breast magnetic resonance imaging in addition to mammography. Currently the World Health Organization does not recommend mammography screening in women less than 50 years of age [4].

Data on the qualitative aspects of the program in the EU states (nature and organization of the program, protocol of

\section{KARGER}

() 2019 S. Karger AG, Basel
Florentia Peintinger, MD 


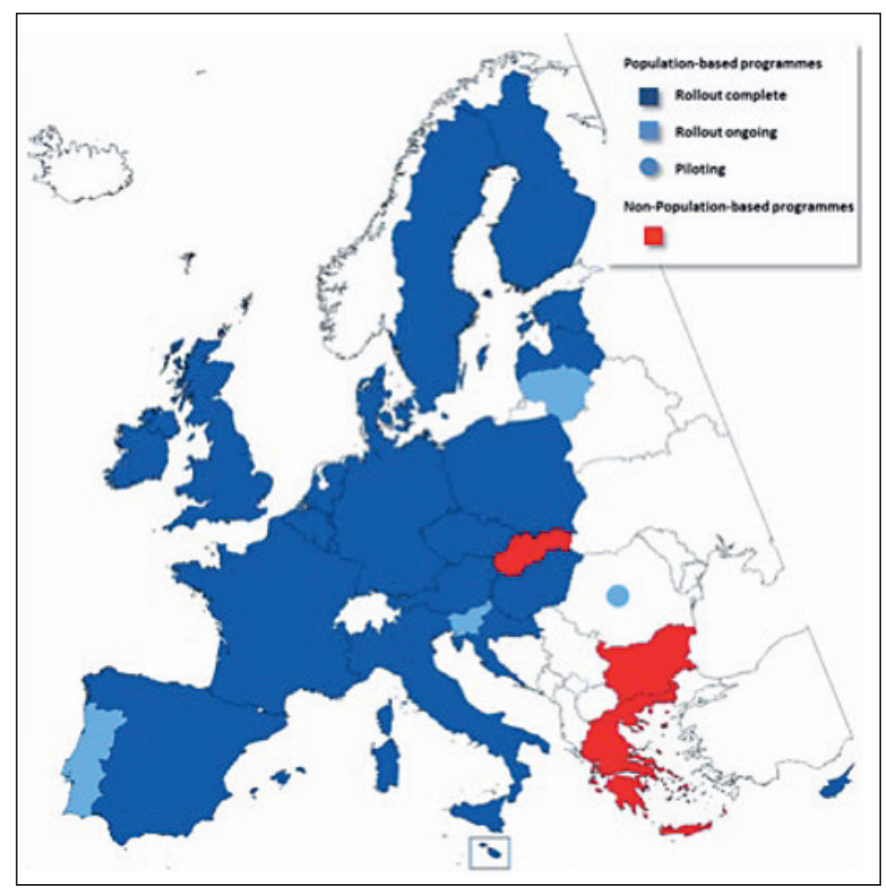

Fig. 1. Estimated number of new breast cancers in women in the EU countries in 2025 compared to 2012. (Population forecasts were extracted from the United Nations, World Population prospects, 2012 revision.) Source: GLOBOCAN 2012 v1.0 [10].

screening and diagnosis, mode of invitation and recall, quality assurance practices etc.) were collected through web questionnaires, filled in for breast cancer by the data providers as on July 1, 2015, and were reviewed [5]. According to the second report on the status of implementation of cancer screening programs, population-based breast cancer screening programs are already implemented, piloted or planned in $25 \mathrm{EU}$ member states for approximately $95 \%$ of women aged between 50 and 69 years [5].

\section{Methods}

We report on current breast cancer screening programs in Europe and indicate possible differences.

Characteristics of the screening programs in Europe are shown in Table 1.

\section{Results}

\section{Screening Techniques}

Mammography is the only screening technique recommended by the European Commission for women aged 50-69 years. Most of the screening programs used digital mammography which shows high sensitivity also in dense breasts and has completely replaced film-screen mammography in $64 \%(16 / 25)$ of the EU states. It has been reported that implementation of digital mammog-

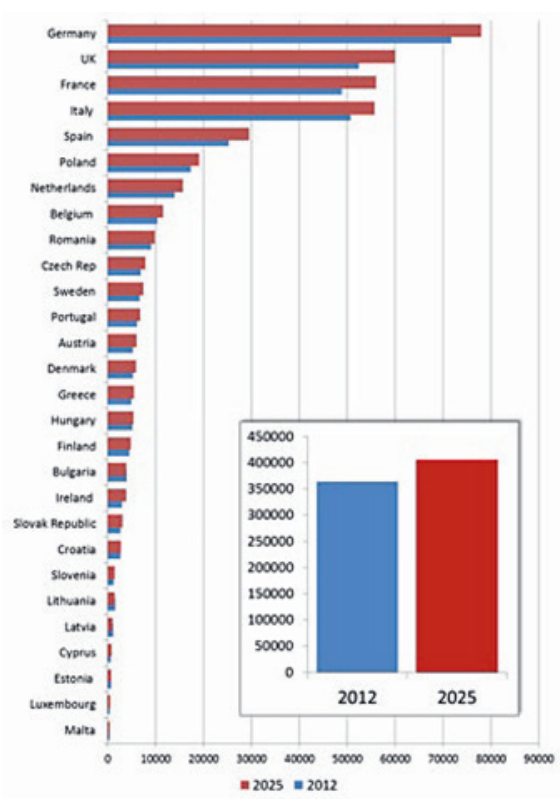

Fig. 2. Breast cancer screening programs in the EU (2016).

raphy in 2007 doubled the referral rates in the Netherlands screening program [6]; sonography was additionally used in a few only screening programs. In the French program clinical breast examination is also used additionally to mammography and sonography. Radiology imaging included two views in all European countries. Information about double reading was not available in Cyprus, Monaco, San Marino and the UK. The Russian Federation does not provide double reading.

\section{Breast Cancer Screening Programs}

All European states except the Russian Federation, Bulgaria, Greece, the Czech and Slovak Republics have population-based breast cancer screening programs (Fig. 2). Participating women in organized screening programs were 50-69 years old when invited for mammography screening in $12 / 29$ (41\%) states. The interval between two mammography tests of screening is 2 years for most of the countries except Malta and the UK which follow a 3-year interval. The second report on the implementation of the Council Recommendation on Cancer Screening [5] indicates that among the estimated 32 million female annual population between 50 and 69 years old in the EU, 78.9\% have been invited to mammography screening in the population-based programs in 2016, and $49.2 \%$ have been definitely screened compared to 43.7 and $28.7 \%$ in 2007 , respectively. However, the participation rate varied among member states between 6.2 and $83.5 \%$, with the highest 
Table 1. Breast cancer screening programs in Europe

\begin{tabular}{|c|c|c|c|c|c|c|c|}
\hline Country & Start & Type & All nation coverage & Test & Double read & $\begin{array}{l}\text { Age screened, } \\
\text { years }\end{array}$ & $\begin{array}{l}\text { Interval, } \\
\text { years }\end{array}$ \\
\hline Austria & 2014 & $\mathrm{~PB}$ & $\mathrm{Y}$ & DM, US & $\mathrm{Y}$ & $45-69$ & 2 \\
\hline Belgium & $2000 / 2001$ & $\mathrm{~PB}$ & Flanders, Wallonie & DM, US & Y if necessary & $50-69$ & 2 \\
\hline Croatia & 2006 & $\mathrm{~PB}$ & - & $\mathrm{DM}$ & & $50-69$ & 2 \\
\hline Czech Republic & 2002 & NPB & $\mathrm{Y}$ & DM, US & $\mathrm{Y}$ & $45-69$ & 2 \\
\hline Cyprus & 2003 & $\mathrm{~PB}$ & $\mathrm{Y}$ & $\mathrm{DM}$ & - & $50-69$ & 2 \\
\hline Denmark & 2001 & PB & $\mathrm{Y}$ & $\mathrm{DM}$ & $\mathrm{Y}$ & $50-69$ & 2 \\
\hline Estonia & 2002 & $\mathrm{~PB}$ & $\mathrm{Y}$ & $\mathrm{DM}$ & $\mathrm{Y}$ & $50-65$ & 2 \\
\hline Finland & 1987 & $\mathrm{~PB}$ & $\mathrm{Y}$ & DM, US & $\mathrm{Y}$ & $50-69$ & 2 \\
\hline France & 1989 & $\mathrm{~PB}$ & $\mathrm{Y}$ & $\mathrm{MM}, \mathrm{DM}, \mathrm{CBE}$ & $\mathrm{Y}$ & $50-74$ & 2 \\
\hline Germany & 2002 & $\mathrm{~PB}$ & $\mathrm{Y}$ & $\mathrm{DM}$ & $\mathrm{Y}$ & $50-69$ & 2 \\
\hline Greece & $2004-2009$ & NPB & Pilot & MM & - & $40-69$ & $1-2$ \\
\hline Hungary & 1995 & $\mathrm{~PB}$ & $\mathrm{Y}$ & $\mathrm{DM}$ & $\mathrm{Y}$ & $45-65$ & 2 \\
\hline Iceland & 1987 & $\mathrm{~PB}$ & $\mathrm{Y}$ & $\mathrm{DM}$ & $\mathrm{Y}$ & $40-69$ & 2 \\
\hline Ireland & 2000 & $\mathrm{~PB}$ & $\mathrm{Y}$ & $\mathrm{DM}$ & $\mathrm{Y}$ & $50-64$ & 2 \\
\hline Italy & $1990-2012$ & $\mathrm{~PB}$ & $\mathrm{Y}$ & DM or DM, US & $\mathrm{Y}$ & $50-69$ & 2 \\
\hline Luxemburg & 1992 & $\mathrm{~PB}$ & $\mathrm{Y}$ & $\mathrm{DM}$ & $\mathrm{Y}$ & $50-69$ & 2 \\
\hline Malta & 2007 & $\mathrm{~PB}$ & $\mathrm{Y}$ & $\mathrm{DM}$ & $\mathrm{Y}$ & $50-60$ & 3 \\
\hline Monaco & 1994 & $\mathrm{~PB}$ & $\mathrm{Y}$ & DM, US & - & $50-80$ & 2 \\
\hline Norway & 1995 & $\mathrm{~PB}$ & $\mathrm{Y}$ & $\mathrm{DM}$ & $\mathrm{Y}$ & $50-69$ & 2 \\
\hline Poland & 2006 & $\mathrm{~PB}$ & $\mathrm{Y}$ & MM, DM & $\mathrm{Y}$ & $50-69$ & 2 \\
\hline Portugal & $1990-2009$ & $\mathrm{~PB}$ & No & $\mathrm{DM}$ & $\mathrm{Y}$ & $45-69$ & 2 \\
\hline Russian Federation & $2007-2012$ & NPB & - & $\mathrm{DM}$ & No & $<40$ & 2 \\
\hline San Marino & 1993 & & $\mathrm{Y}$ & DM, US & - & $35-74$ & 2 \\
\hline Slovakia & - & NPB & - & - & - & $40+$ & 2 \\
\hline Slovenia & 2008 & $\mathrm{~PB}$ & - & $\mathrm{DM}$ & $\mathrm{Y}$ & $50-69$ & 2 \\
\hline Spain & $1990-2001$ & $\mathrm{~PB}$ & $\mathrm{Y}$ & $\mathrm{DM}$ & $\mathrm{Y}$ & $45 / 50-69$ & 2 \\
\hline Sweden & $1986-1989$ & $\mathrm{~PB}$ & $\mathrm{Y}$ & $\mathrm{MM}, \mathrm{DM}$ & $\mathrm{Y}$ & Diff./region & $1.5-2$ \\
\hline Switzerland & 1999 & $\mathrm{~PB}$ & $\mathrm{Y}$ & MM, DM & $\mathrm{Y}$ & $50-70$ & 2 \\
\hline The Netherlands & 1989 & $\mathrm{~PB}$ & $\mathrm{Y}$ & $\mathrm{MM}, \mathrm{DM}$ & $\mathrm{Y}$ & $50-75$ & 2 \\
\hline United Kingdom & 1989, 2004 & $\mathrm{~PB}$ & $\mathrm{Y}$ & $\mathrm{DM}$ & - & $50-70$ & 3 \\
\hline
\end{tabular}

MM, mammography; DM, digital mammography; US, ultrasound; CBE, clinical breast examination; Y, yes; PB, population based; $\mathrm{NPB}$, not population based; diff./region, different depending on region.

participation rates observed in Denmark and in Slovenia (Table 2). Overall recall rates for initial and subsequent screening examinations were lowest in the Netherlands $(2.3 \%)$ and highest in Malta (13.0\%) (Table 2).

The mean detection rate of any cancer (carcinoma in situ and invasive cancer) at a subsequent screening was 6.2/1,000 (range 2.2-10.1) women screened between 50 and 69 years, and the positive predictive value of mammography to detect any cancer was $12.2 \%$ (range $4.4-$ 27.9 ) in the screened age group [5]. The detection rate of invasive cancer only was $5.18 / 1,000$ (range $1.8-8.0$ ) with the highest detection rate in UK Wales.

\section{Conclusions}

Breast population-based screening (persons are individually identified and personally invited to attend screening) is intended to detect breast cancer at an early stage to enable lower mortality rates. Eligible women aged mainly from 50 to 60 years receive an invitation letter explaining the aim of the screening. Implementation of the recommended maximum age range was adopted in most programs. Almost all the countries established digital mammography as the method of screening instead of screen-film mammography. Additional ultrasound imaging is offered only in a few programs. Screening mammography before the age of 50 years is controversial and offered only in a few states. Recently the European Commission Initiative on Breast Cancer (ECIBC) published that for asymptomatic women aged 40-44 years with an average risk of breast cancer, the ECIBC's Guidelines Development Group suggests not implementing mammography screening (conditional recommendation, moderate certainty in the evidence) [7]. Age extension is part of a study in the UK looking at whether to extend the mammography screening age range. The screening interval recommended is 2 or 3 
Table 2. Screening quality parameters, EU member states, 2016

\begin{tabular}{lcc}
\hline Country & $\begin{array}{l}\text { Recall } \\
(50-69 \text { years }),\end{array}$ & $\begin{array}{l}\text { Participation } \\
(50-69 \text { years }), \\
\%\end{array}$ \\
\hline Austria & 2.4 & - \\
Belgium & $2.6-11.8$ & $6.2-48.6$ \\
Croatia & - & 43.1 \\
Czech Republic & 7.7 & - \\
Cyprus & 10.1 & 37.7 \\
Denmark & 2.6 & 83.5 \\
Estonia & 2.6 & 66.3 \\
Finland & 2.6 & 83.0 \\
France & 9.4 & 51.0 \\
Germany & 4.6 & 56.3 \\
Hungary & 6.1 & 59.0 \\
Ireland & 3.8 & 68.7 \\
Italy & 5.8 & 55.4 \\
Luxemburg & 6.0 & 56.6 \\
Malta & 13.0 & 58.1 \\
Poland & 4.0 & 63.1 \\
Portugal & $1.6-5.8$ & $58.5-66.8$ \\
Slovenia & 3.5 & 82.5 \\
Spain & 4.5 & 70.4 \\
Sweden (regions) & 2.4 & 73.2 \\
The Netherlands & 2.3 & 80.1 \\
United Kingdom & $3.9-5.0$ & - \\
\hline
\end{tabular}

years. According to the European guidelines $70-75 \%$ of eligible women should attend screening. Recent data have shown a lower participation rate in most states. Also, several states still have no population-based screening program. There are also significant differenc- es in mortality rates between countries for these same cancers. Although recall rates exceeded the desirable lower levels, breast cancer detection rates were relatively high.

Altobelli and Lattanzi [8] reviewed breast cancer screening programs in 2014 in the EU and found substantial improvement in the further implementation of population-based breast screening programs. They noted that national policies and health care systems should plan to maximize participation in controlled organized screening programs, by means of factors such as campaigns identifying and lowering any barriers to adhesion, also with a view to reducing health care costs. Countries such as Austria, Denmark, France, Iceland and the Netherlands lack prevention campaigns for breast cancer risk factors. Greece, Hungary, Luxemburg and Russia lack high-quality data in order to estimate breast cancer incidence and mortality.

Inequalities in implementation of cancer screening in the EU may be a result of variabilities in economic resources for health care among the states [9].

Emerging goals of the Council recommendation on cancer screening is to improve the quality of data. For this adequate health information systems linked to the screening programs with existing cancer and mortality registries are needed.

\section{Disclosure Statement}

The author declares no conflicts of interest.

\section{References}

1 Steliarova-Foucher E, O'Callaghan M, Ferlay J, Masuyer E, Forman D, Comber H, et al. European Cancer Observatory: cancer incidence, mortality, prevalence and survival in Europe. Version 1.0 (September 2012). European Network of Cancer Registries, International Agency for Research on Cancer. Available from: http://eco.iarc.fr

2 Council recommendation of 2 December 2003 on cancer screening (2003/878/EC). Off J Eur Union. 2003;327:34-8.

3 New EU guidelines on breast cancer screening and diagnosis. European Commission Press Release Database. Brussels, 2006. Available from: http://europa.eu/rapid/press-release_MEMO-06-161_en.htm
4 http://www.iccp-portal.org/resources/whoposition-paper-mammography-screening 2014

5 https:/ec.europa.eu/health/sites/health/files/ major_chronic_diseases/docs/2017_cancersc reening_2ndreportimplementation_en.pdf

6 Timmers JM, den Heeten GJ, Adang EM, Otten JD, Verbeek AL, Broeders MJ. Dutch digital breast cancer screening: implications for breast cancer care. Eur J Public Health. 2012 Dec;22(6):925-9.

7 https://ecibc.jrc.ec.europa.eu/
8 Altobelli E, Lattanzi A. Breast cancer in European Union: an update of screening programmes as of March 2014 (review) [Review]. Int J Oncol. 2014 Nov;45(5):1785-92.

9 Altobelli E, Rapacchietta L, Angeletti PM, Barbante L, Profeta FV, Fagnano R. Breast Cancer Screening Programmes across the WHO European Region: Differences among Countries Based on National Income Level. Int J Environ Res Public Health. 2017 Apr; 14(4):452.

10 GLOBOCAN 2012 v1.0. Cancer incidence and mortality worldwide: IARC cancer base No. 11 [Internet]. Lyon: International Agency for Research on Cancer; 2013. Available from: http://globocan.iarc.fr 